\title{
An Application of Systems Thinking for Solving Inventory Management Problems
}

\author{
Siraprapa Kositphon ${ }^{a}$ and Paveena Chaovalitwongse ${ }^{\mathrm{b}, *}$ \\ Department of Industrial Engineering, Faculty of Engineering, Chulalongkorn University, Bangkok 10330, \\ Thailand. \\ E-mail: asiraprapa.kos@student.chula.ac.th, bpaveena.c@chula.ac.th (Corresponding author)
}

\begin{abstract}
This study is motivated by the fact that inventory management problem is focused throughout the industrial firms nowadays as well as inventory management problems are not easy to be appropriately solved. According to the concept of systems approach can better give more effective result especially when applied to complex problems. In this paper, we propose a systems thinking framework for solving real-world inventory management problems. The systems thinking framework comes with three case studies to enhance better understanding of how to apply the framework with problems. This study aims to bring about the ideas for solving inventory management problems in more practical fashion. In addition to benefit the development of the proposed framework, the instructors and the industrial firms will gain the high-performing students or workers, who can get to the point of problem and can propose the reasonable solution to effectively dealing with problems. Moreover, this study can be used as a guideline for engineering educators to develop other meaningful methods in advances. We expect that if the case studies are collected much enough, the knowledge-based system for solving inventory management problems can be built for easy investigation to whom have the interest in solving inventory management problems.
\end{abstract}

Keywords: Systems thinking, inventory management, framework, case study.

ENGINEERING JOURNAL Volume 20 Issue 5

Received 20 September 2015

Accepted 8 February 2016

Published 25 November 2016

Online at http://www.engj.org/

DOI:10.4186/ej.2016.20.5.67 


\section{Introduction}

The approach of systems thinking focuses on dividing the whole systems into the subsystems which relate to one another [1]. The major benefit of systems thinking is to help constructing a holistic view of the system so the overall advantages and disadvantages following alternatives are better revealed, which can lead to more effective decision making. The traditional approach, in contrast, focuses on some spots of the system so it might lead to the significant loss without realizing it [2]. Moreover, the character of systems thinking makes it extremely effective on the most difficult types of problems to solve such as the NASA's task of landing a man on the moon and returning that man safely to earth in the early 1960s [1]. None of the technology to accomplish this task existed in that time; therefore this task becomes very complex because there are many issues which need to consider. Some of the problem is that how to assembly three millions parts of the rocket to stand around thirty-six stories high. According to NASA's engineers used the process of decomposing the problem into manageable subsystems and components, the task is easier and the result is so successful. We can say that they applied the concept of systems approach for making the effective result.

Nowadays, many industrial firms faced with inventory management problems that must decide how much to order in each time period to meet the demand for their products [3]. Ineffective inventory management can ruin the business [4]. For example, Nike's problem stemmed from inaccurate demand forecast. Due to their software had bugs and errors, therefore it produced the erroneous forecast which is used to launch the manufacturing plan. As a result, they did not have enough products to respond the customers' demand and overproduced on items that were not sold. According to the lack of a good inventory control, it led to the loss of approximately 100 million dollars in sales [5]. Another instance, Walmart lost 3 billion dollars in sales due to out of stock of the merchandises while their inventory grew at a faster rate than its sales. The fact revealed the cause of problem is that the store backrooms are out of control. A combination of poor procedures and too few payroll hours allocated for managing the space make it almost impossible to find the product when it needed [6]. According to the example, if inventory management problems can happen to some of the famous companies in the world, it can happen to all of the industrial firms as well. Although, the cause of the problem revealed seem so little but its effect is not likewise little. Furthermore, the businesses have emerged with inventory management by using the different strategy. Companies like Dell and Amazon.com have used supply chain management and inventory management to achieve a great success. As, between 1995 and 2005, Toyota carried 30 fewer days of inventory than other General Motors, giving they immense advantage than other companies [7]. These are evident that inventory management problems merit very close attention. Therefore, all of the industrial firms nowadays give precedence in their inventory management.

It is obviously that the inventory management is a very important part of the firms nowadays. Since the inventory management problem is hard to deal with by using the unstructured method [8], we propose an idea of developing the systems thinking for solving inventory management problems. It is strongly possible to get better result of solving the inventory management problems by applying the systems approach. In addition, the proposed systems thinking framework can enhance the insight development in solving the real-world inventory management problems in advance $[9,10]$. Our study based on assumption that the practitioners have fundamental knowledge about inventory management beforehand such as the basic inventory models, the performance measures of inventory, and inventory related costs. Thus, we mainly emphasize to present the problem-diagnosis in each case study as well as the solution is briefly concluded.

The three case studies presented in this paper are examples of generic inventory which can be found in either manufacturing sector or service sector. The inventories of raw material and finished goods which are commonly found in manufacturing sector are presented in Case Study 1 and 2 respectively. Case Study 3 represents the inventory problem that can be found in the service sector. These three case studies aim to demonstrate how the proposed framework can be used in various environment setting.

The rest of this paper is organized as follows: (2) Characteristic of inventory problems, (3) Systems thinking framework design, (4) The proposed systems thinking framework, (5) Case study of design of purchasing management for imported raw materials, (6) Case study of improvement of tissue paper conversion planning, (7) Case study of equipment planning model for retails store network of coffee-bakery shop, and (8) Discussion. 


\section{Characteristic of Inventory Problems}

Inventory problems occur as a result of unsynchronized flows between demand side and supply side. In order to appropriately synchronize both sides of the inventory flow, it involves various information and factors. Thus the characteristics of inventory problems in practice rely purely on those information and factors such as types of inventory (e.g. raw material inventory, finished goods inventory, spare parts, etc.), business background (e.g. business sector, business competitive strategy, marketing strategy, manufacturing types, etc.), properties of inventory (e.g. shelf life, values, substitutable items), demand information (e.g. who demand the inventory, level of information certainty, pattern of demanding, etc.), and supply information (e.g. limited or infinite supply, constraints on supplying, lead time, sources of supplies, level of information certainty, etc.). With different settings of information and factors, it results in various inventory problems in term of objective setting, constraints, parameters, and source of information. For example, in raw material inventory (types of inventory) problem in manufacturing sector (business background), the demand information can be found from production planning (who call for the raw materials) where it is the result of manufacturing strategy (business background), the supply information can be retrieved from supplier database (who supply the raw materials). Moreover, when determining the solution, the objective, constraints, and parameters can be set differently among raw materials depending on the material itself in term of company strategy, manufacturing constraints, supplier constraints, level of criticality when shortages occur, item's value, etc. It is obviously seen that there can occur tremendous amount of inventory problem settings. Thus the important characteristic of inventory problems found in real-world is dynamic with multi-dimensional information of the inventory system setting. Even if it is impossible to restrict the dynamic situation in real-world inventory management problems, it is still possible to reduce the impact of such fluctuations on business in general [11]. This can be done if the business sets some direction to hold a smaller volume of inventories but it still can respond to fluctuations. Then, inventory policy must be the answer because inventory policy is a standard set of rules or boundaries or guidelines that provide the framework for organization to make the optimal quantity as well as timing. The benefit of inventory policy setting is not only to help workers working easily but also it allows company to develop a cost advantage in the economic market situation [12].

\section{Systems Thinking Framework Design}

An idea of this study rises from our intention to develop a guideline framework to deal with inventory management problems regarding inventory policy setting because the real-world inventory management problem is very complex and influenced by various factors, constraints, and information needed. Additionally, an effective solution for solving inventory management problems should conform to the competition policy of the company. For example, if the solution emphasizes to reduce inventory related costs but the competition policy of the company mainly focuses to respond to the customers' demand, the overall result of inventory management following the solution cannot definitely satisfy to the company's target. Moreover, it still has not had the exact procedure of existing analysis tool. The existing procedures are differently and widely among the analysts following their experiences and proficiencies in solving the problems. Therefore, the proposed systems thinking framework attempts to promote how to think or analyze about the inventory problem rather than telling what to do in term of solution. The framework aims to be a guideline of problem analysis especially for those who have no experiences in solving the realworld inventory management problems beforehand.

Since the inventory problems are dynamic and dealing with multi-dimensional information of the inventory system setting, there is a need for a framework to gather multi-dimensional information. In addition, there is also a need for a platform to analyze those gather multi-dimensional information effectively and efficiently.

According to the engineering education literature [15], the concept of systems approach is applied to the learning platform to develop the steps for solving the problem in system engineering. They define the objective and tasks of each step, which lead to the reasonable solution for solving the problem. In addition, the systems approach helps in producing a better result more quickly and with less effort [1]. When the system is classified into subsystems, it will be easier to be managed. [13, 14]. It clearly shows the inside relation among the actors, the constraints, and the data. Moreover, when the subsystems are merged into the system, the outside relation can be seen as well. 
In the proposed framework, the concept of systems approach is applied in the data analysis platform. The systems approach's concept helps to guide how to logically think before taking the actions especially to think of the effects of course of action to the overall level of management not only for solving the inventory's section so that solution will be the sustainable solution for the company. Some logical questions or thinking needed to be answered before taking actions are as follows: What is the purpose of the action? How does the action affect to the section of inventory management, and Will this action give the benefit to the overall company's situation? In conclusion, the proposed systems thinking framework is designed to enhance the practitioners to analyze and solve inventory management problems effectively. Because the proposed framework considers many dimensions of information so it can help the practitioners to predict the effect of the solution to inventory's section and the overall benefit to the company.

The proposed framework is designed to guide about gathering the appropriate information and building some ideas for problem analysis using the concept of systems approach as well. The framework encompasses two components: essential data and systems thinking process. Firstly, the component of essential data aims to gather necessary data for problem analysis in organized way. This component encompasses general background information and the inventory system related information. We design the given information to be multi-dimension e.g. the business, the supplier, the customer, the item, the manufacturing system, and the current inventory management policy. The multidimensional information will help the practitioners to see a big picture of overall problem. Therefore, they can construct an openended problem in practical situation, propose many related solutions, predict how those solutions affect other dimensions, and finally make the decision of the suitable solution that conforms to the current situation and characteristic of the business. Secondly, the systems thinking process provides the flow of systems thinking which includes three systematic steps: 'recognize suffering', 'analyze causes of suffering', and 'propose solution'. Figure 1 shows the overview of the proposed framework. Note that the underlining in Fig. 1 represents the linkage of analysis's results between connecting steps.

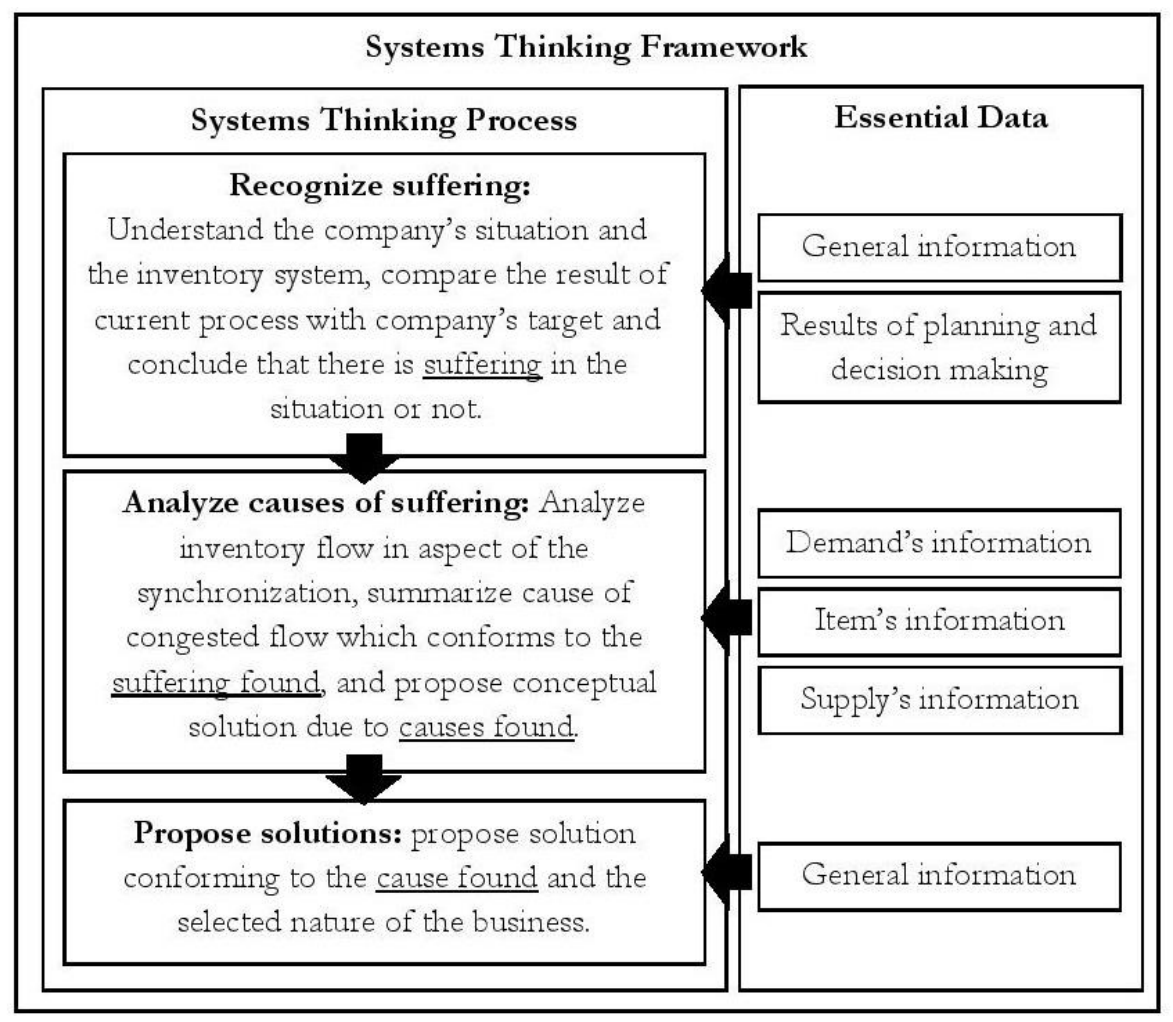

Fig. 1. Overview of systems thinking framework for inventory management problems.

\section{The Proposed Systems Thinking Framework}

The detail description of the proposed framework is presented as follows. 


\subsection{Essential Data}

The essential data mean the information which essentially involve for analyzing the inventory management problems. The background information include of the company's business, the key success of the business, the company's policy, and the current inventory system of the company. We must understand the company's situation before analyzing the problem in the situation. Afterward, the inventory system is recognized. The inventory system related information consist of the item's information (what are the focus inventories? and what are their special characteristics?), the demand's information (who call for the item? and how do they call?), and the supply's information (who supply the item? and how do they supply?). When the three groups of information are consolidated, it will become a big picture of the inventory system. We also name the big picture of the inventory system as the inventory flow. Inventory flow is the method to cross- check the consistency between the demand-supply characteristic and the current procedure for matching them. More specific details of the information are presented in the following paragraphs. The details of essential data are summarized as shown in Fig. 2.

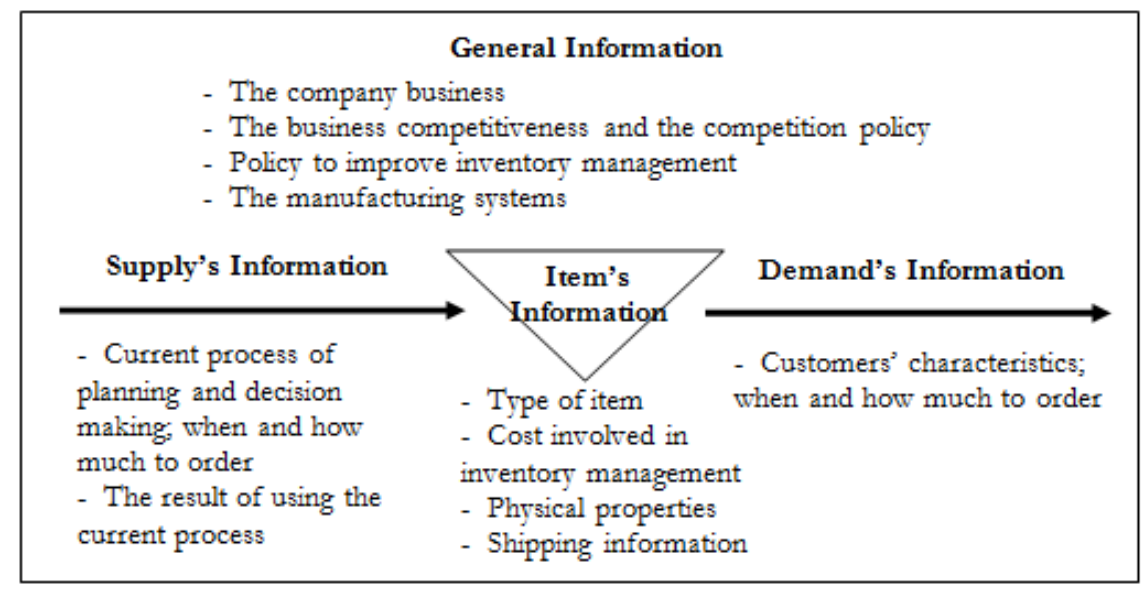

Fig. 2. Essential data for analyzing inventory management problems.

Firstly, the topics in general information are as follows: (1) the company business, (2) the business competitiveness and the competition policy, (3) policy to improve inventory management to response to the competition policy, and (4) the manufacturing systems such as manufacturing processes, processing time and variety of products in each process. Secondly, more than the understanding throughout the business, the important information, which is the core of analyzing the inventory problems, is the item's information. We should know the (1) type of item, which can be the raw material, the finish goods, the work in process, or the spare part, (2) the cost involved in inventory management, and (3) the physical properties of the item such as life span and storage requirement, and (4) the shipping information which describes delivery channels, the lead-time for supplying, the lead-time's fluctuation, purchasing options, and promotions. Type of the item helps us selected the proper information of the demand and supply of the focused item for analysis, while the rest of information will support the analysis of the inventory flow. Thirdly, the demand's information, which is related to the focused item, is about the customers' characteristics. The information must answer the questions that are when customer will order, how much they order, and how is the demand's fluctuation. Finally, the supply's information include of (1) the current process of planning and decision making, which relates to inventory management policy such as what should the company order, when and how much to order and (2) the results of current process of planning and decision making.

\subsection{Systems Thinking Process}

Systems thinking process is introduced to help in formulating the problems, analyzing causes of problems, recommending the possible and reasonable solution. It includes three steps which link between each other to achieve the goal of solving the inventory management problems. 
First step is 'Recognize Suffering'. In this step, we will understand the company's situation and the inventory system first. Then, the undesirable or unpleasant event will be detected. We name that event as the suffering. The way of detecting is by comparing the result of using the current process of planning and decision making with target goal of the company. If the results are off the target, an inventory management problem is believed to exist in the company's situation.

Next step is 'Analyze Cause of Suffering'. After we found the unpleasant event in the situation from previous step, a cause which leads to that event is identified in the next. The approach of identifying is by analyzing the synchronization of the demand's characteristic, the supply's characteristic, item's characteristic, and the current process of planning and decision making. If some characteristics are not synchronized with some procedures in the process of planning and decision making and it may trigger cause, those procedures are justified as causes of the problem in the company's situation. After causes of the problem are identified, the conceptual solution conforming to the finding causes is proposed that is the final output of this step.

Final step is 'Propose Solution'. The proposed solution is gained by synthesizing the combination of the conceptual solution from analyze cause of suffering's step and some nature of the business, which are understood in the recognize suffering's step. The proposed solution may be one of many possible solutions which is proved that it is workable for current company's situation. In addition, the solution is presented briefly based on assumption that users have fundamental knowledge in inventory management beforehand. In conclusion, the systems thinking process is to start with recognizing suffering from a given scenario and identifying evidence support for the existence of suffering. Afterwards clearly sufferings are defined, analysis causes of suffering is a next step. In this step, not only causes are identified but conceptual solutions are begun to describe as well. Final step, a linkage from abstract to concrete solution is presented following the cause found. Moreover, the proposed solution must conform to some nature of the business as well. Section 5, 6, and 7 demonstrated how to use the framework in case studies.

Figure 3 presents a clear picture of the systematic viewpoint to analyze or solve inventory problems by the proposed framework. The interrelations among pieces of information are a guideline for the practitioners to trace back to the reason of the action before taking. Note that the underlining phases in Fig. 3 represent the output that will consequently be used to analyze in other steps.

\section{Case Study of Design of Purchasing Management for Imported Raw Materials}

This case study aims to present a method to design an appropriate policy for imported raw materials. Specific characteristics of this case is that as-is ordering procedure does not correspond well with the nature of demand's characteristic, which fluctuates with high level of forecast errors. Moreover, according to the situation that material is imported so the supply's lead-time is much longer than customers' lead-time. An effect of fluctuated demand in long lead-time is the cause of higher demand's fluctuation.

\subsection{Recognize Suffering}

\subsubsection{Understand the company's situation}

The company's business: The Company is a high quality leader in producing steel wire rods. Company's wire rods have a round cross-section and vary among grades and sizes. In general, steel wire rods are used in various fields such as automobile, construction, and heavy industry. For this case, main customers of the company are in construction's field, for example, a contractor and a master builder.

The business competitiveness, competition policy, and policy to improve inventory management: Since to wire rods are a commodity product, the key success factor of the business composes of price and quick response to customers' demand. In addition, now the company also launches a new competition policy to increase competitive advantage by reducing costs of inventory management while customer service level retains or increases. The benefit of cost reduction is to generate incremental gross profit to the company. Then, the incremental profit can be used in many aspects to increase the competitive advantage, e.g., releasing a new promotion or advertisement, and investment in a new technology to increase products' quality. Besides, if service level is also increased, it directly affects to the key of quick response to customers' demand. When service level is improved, it may also augment customer satisfaction, which is essentially factor in building long-term profit of the company in the future. 


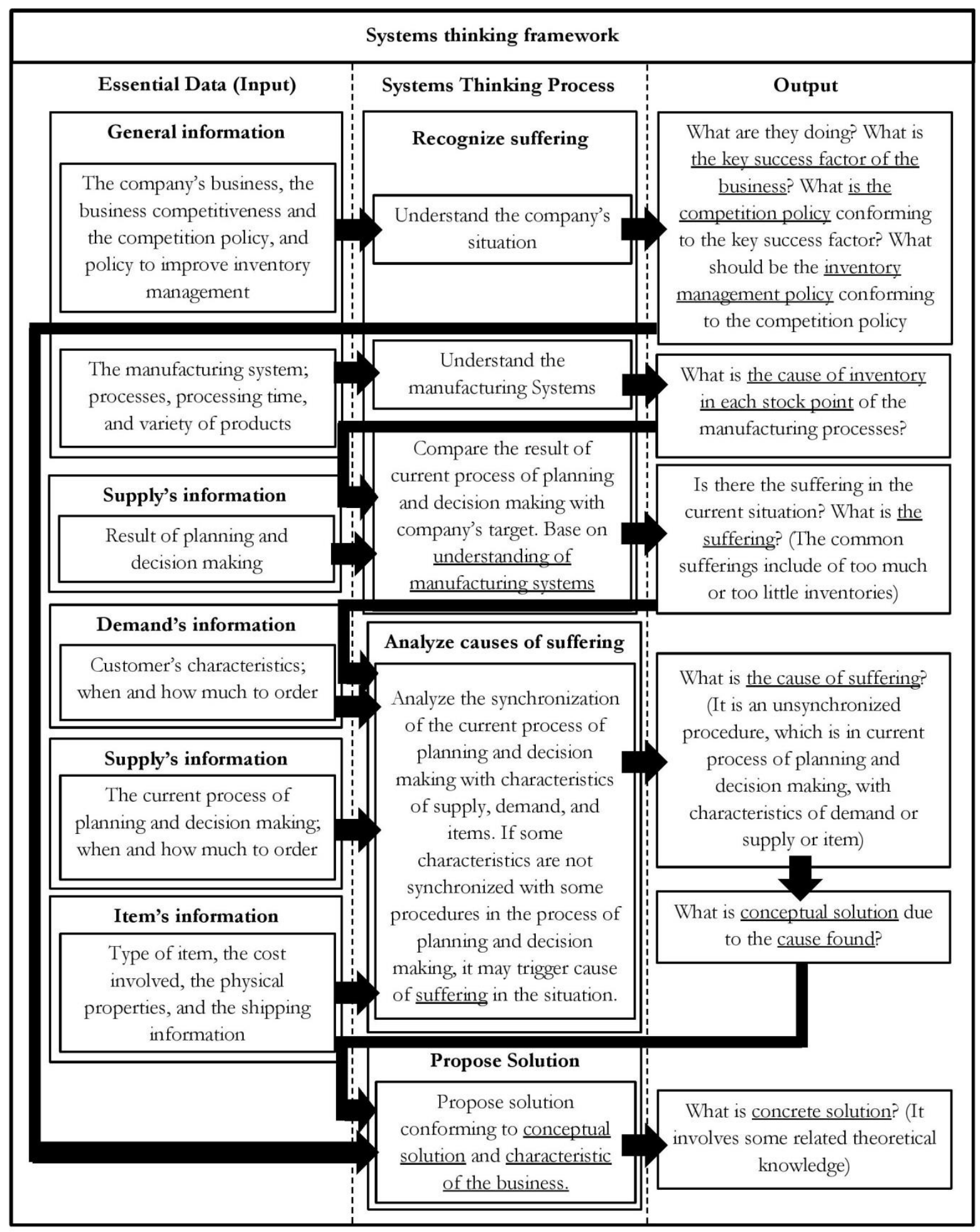

Fig. 3. Systems thinking framework for inventory management problems.

\subsubsection{Understand the inventory system}

The manufacturing systems: Wire Rod is a final product of the company. The manufacturing processes to produce wire rods start from scraps melting process, and then three types of raw materials to refine the scraps' properties are added, which are additives, alloys, and refractory. The ingredients to refine the properties can be varied following the bill of materials or the product structures. Afterward, casting process is conducted, and then billets are gotten to be the output of this process. There are many grades of billets 
existing following the different product structures. Finally, billets are heated and rolled until they become wire rods in many grades and diameters. The entire manufacturing processes are summarized in diagram as shown in Fig. 4. In Fig. 4, processing times are in a minute while some of materials are imported. According to imports take a long time to deliver, so the most inventories in a company's warehouse is raw materials, which is around $45 \%$ of overall inventories. The company's policy is that they will stock inventories for avoiding the production standstill situation. Thus, this case study mainly focuses on the management of imported raw materials, which is the major of overall inventories.

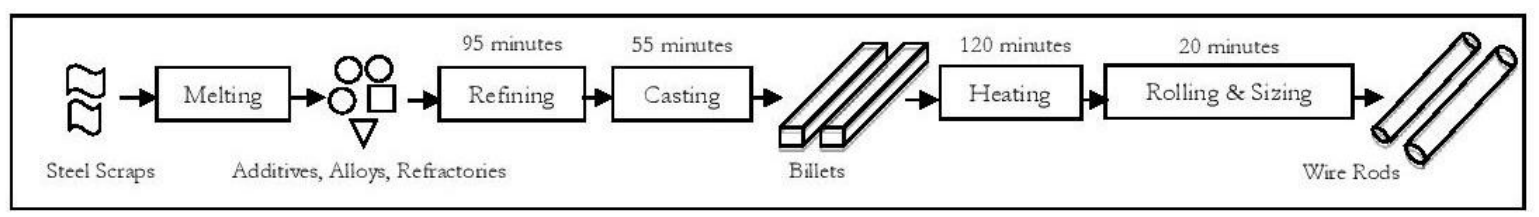

Fig. 4. Manufacturing processes to produce steel wire rods.

Demand's information: Customer's demand for this case is uncertain and difficult to predict in both dimensions of quantity and time. It is because steel's price is unstable so the customer will not confirm purchase order very well in advance due to the price speculation. This effect also continues to the demand of raw materials becoming uncertain and difficult to predict.

Item's information: Due to their raw materials are shipped, so it takes a long time for delivery and includes many uncontrollable factors. Those directly affect time consumption in supplying the raw materials. Some of uncontrollable factors are weather and conditions of full container load. As abovementioned, the lead-time in supplying the raw materials behaves unpredictably.

Additionally, special characteristic of the focused raw materials is they are able to joint ordering. That is a result from the company orders many types of raw materials by the same supplier. Furthermore, there are also options of full container load existing for imported materials. Both characteristics, which are joint ordering and full container load, can be use as options for setting an appropriate inventory management policy in future.

Supply's information (the current process of planning and decision making): Currently, the company deals with demand by launching a production plan which relies on the data of demand forecasting. The company will forecast the customers' demand for wire rods ahead of 7 months. At the beginning of each month, the forecasting data of 1 month ahead is confirmed. However, the confirmed data can be changed overtime due to planner's consideration conforming to an actual occurrence. Then, the demand of wire rods from the forecasting will be transferred into the demand of raw materials following the product structures. According to supplying lead-time is around 2 months while the confirmed data is 1 month ahead, so the data which are used for launching the purchase order of raw materials will include non-confirmed data as well. Therefore, the forecast error trends to exist in a high level. Moreover, due to imported materials have a long lead-time in supplying, the existing error is possible to be in higher than usual, if we consider following the theory of inventory management. Currently the purchase order policy will be launched once in a month. The amount of order is acquired from calculating the data of demand forecasting, current inventory on hand, and target stock level. In this case, target stock is set around an average of customers' demand for 1 month.

Supply's information (the result of using the current process): Due to results of using current inventory management policy; although, the company's inventory turnover performs better than the last year as seen in Fig. 5 but if we consider the result of benchmarking of the raw materials' turnover among the competitors from Fig. 6. It shows that the company's turnover becomes the worst. Inventory turnover is a measure of the company's ability to flip its products for cash. Therefore, the lowest turnover indicates that the company can flip inventory for cash slowly. That is the reason why the company launches the new policy to improve performance of inventory management. In addition, there is also a signal of using unsuitable policy existing in current situation that is a shortage of raw materials occurs intermittently overtime [16]. 


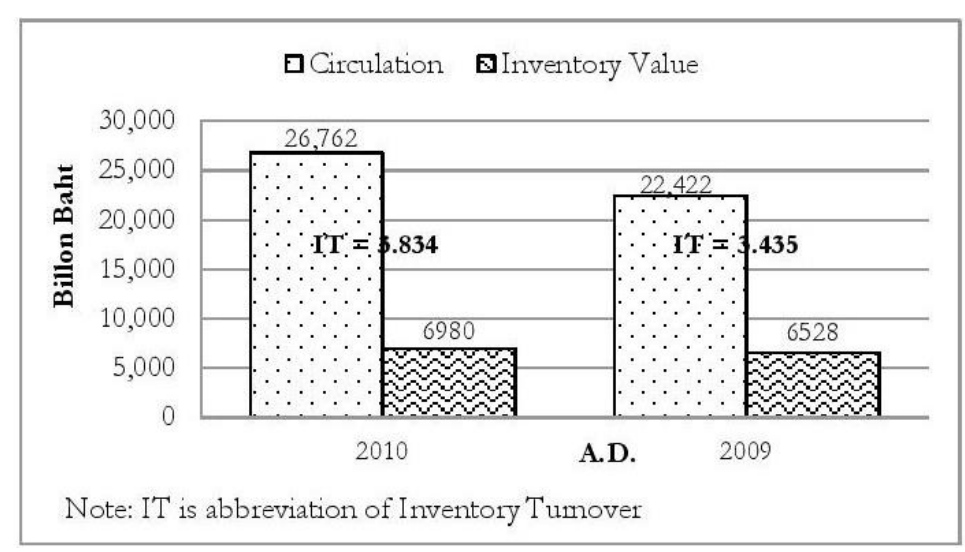

Fig. 5. Company's inventory turnover.

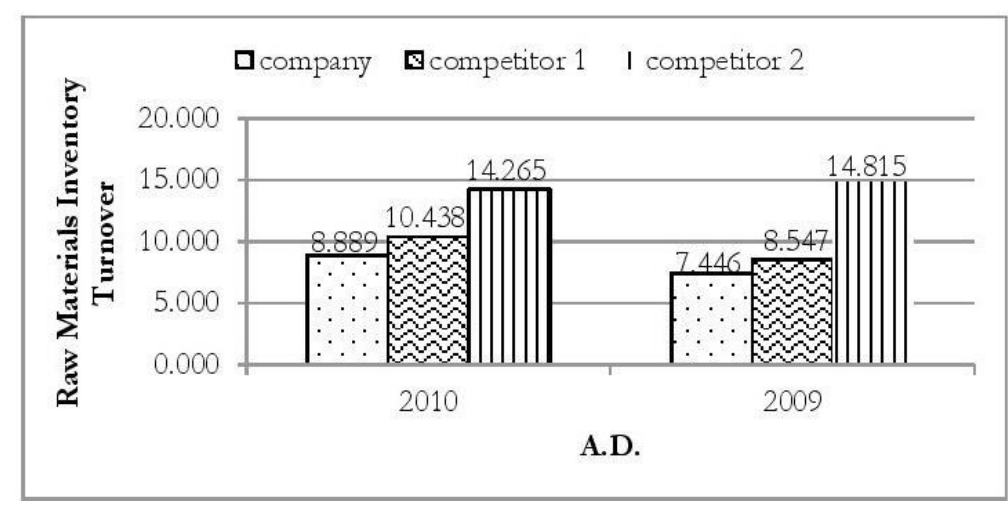

Fig. 6. Results of benchmarking among the competitors.

5.1.3. Compare the result of current process company's target and conclude the suffering

The selected result from using current process to launch the purchase order is inventory turnover. Inventory turnover is used like an indicator to compare performance of an actual occurrence with a company's target. A selected method of comparing is benchmarking with the competitors. Therefore, the company's target becomes aiming for higher inventory turnover than the others. However, the comparing result found that company's inventory turnover is lower than other companies, as seen in Fig. 5. This can be inferred that the company might stock too much inventories. Moreover, we found that the shortage intermittently occurs as well. Those lead to the question of why raw materials are still short even if we stock too much. Thus, the conclusion in recognize suffering is that there is an inventory management problem existing in the company's situation.

\subsection{Analyze Cause of Suffering}

\subsubsection{Analyze the inventory flow and summarize cause of suffering which leads to the suffering}

The focused inventories in this case are imported raw materials. Currently the imports are called from production plan and are supplied by purchase order. Then, we will sum up the demand's and the supply's characteristics, and the current inventory management policy of the company. According to information from case scenario, we found that the demand and lead-time in supplying are uncertain as well as the current policy mainly purchases following monthly forecasting's data. Fig. 7 shows more details about the demand, the supply, and the inventories as a diagram which we call it as an inventory flow. Afterwards, the suitability analysis is initiated to find out how well of the synchronization between the characteristics. We found that the current purchasing policy is not synchronized to the occurrence of demand's fluctuation. Actually, fluctuations in both the demand and lead-time in supplying can support by safety stock. Due to the current policy, safety stock is set upon an average demand for 1 month and it is just estimation. 


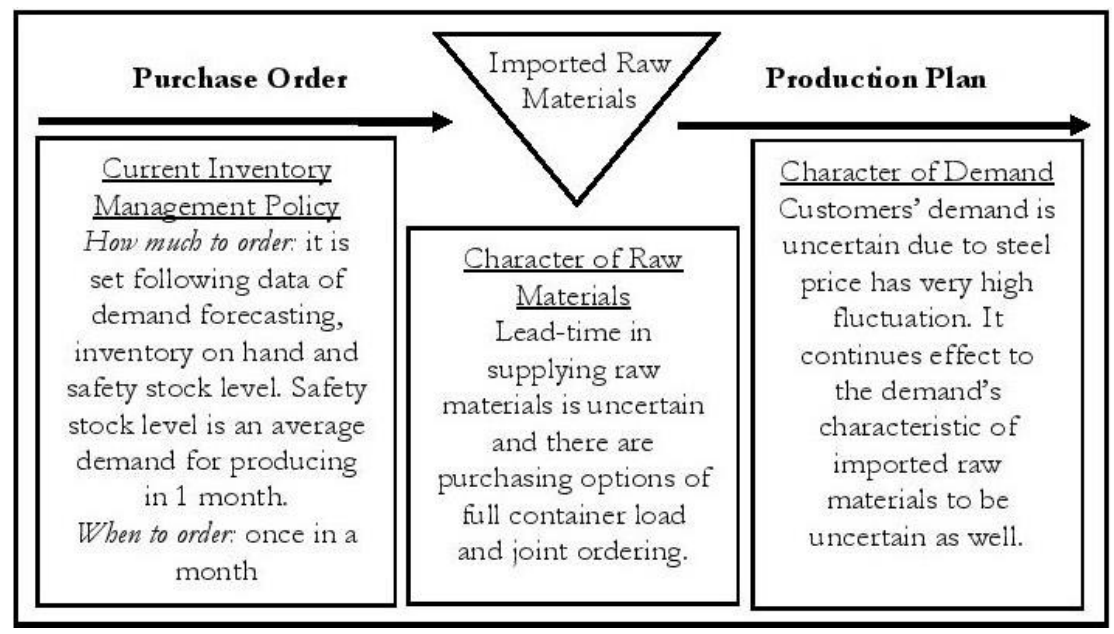

Fig. 7. Inventory flow of imported raw materials.

\subsubsection{Proposed the conceptual solution due to cause found}

The suggested conceptual solution for setting inventory policy is that the company should involve the fluctuation which reflects to actual occurrence. The proposed conceptual solution tends to lessen problem in current company's situation because the advantage of having safety stock level conforming to the demand's characteristics is cause for better matching between the demand and supply. Continuous effect is to increase turnover as well. That directly amends performance of inventory management, which is a company's target for now.

\subsection{Propose Solution}

\subsubsection{Propose concrete solution due to cause found and the selected nature of the business}

The concrete solution, which can be applied, is the fixed order quantity system or the fixed order period system because both systems concerning in forecast errors and uncertainty of demand during lead-time [17]. Moreover, due to the demand's characteristic is unstable overtime, the fixed order quantity system may be the best choice for the company [18]. As a result of the fixed order quantity system is able to track the change of demand better than the fixed order period system, so it is more suitable with the situation of high level of demand's fluctuation. In addition, due to the particular characteristic of the imports, there is a shipping option of full container load existing to consider. Another option, which is possible, is joint ordering. Joint ordering can be done when the company orders many products from one supplier same as this case.

In brief, there are three options for setting new policy that are 'the fixed order quantity system (Option 1)', 'the fixed order quantity system adjusted by shipping option of full container load (Option 2)', and 'the fixed order quantity system with joint ordering (Option 3)'. The simulation's results are run through historical data of the company as shown in Table 1 and 2. Table 1 illustrates the result in aspect of the cycle service levels while the costs' aspect is presented in Table 2. According to the result shown, we can sum up that option 3 is the best fit for the company's situation because it can retain 100\% of service levels and give the lowest total cost as well. Nevertheless, this summing-up is valid upon the belief that the certain patterns in history repeat themselves.

The core of proposed policy is to adapt stock level following the actual occurrence. This doing is cause of better inventory flow if comparing with the old one which is just estimation. In addition, according to option 3 is fittest to the company's situation, it refers that the ordering cost is the biggest part of the cost of inventory management for this case. That is possible because the raw materials are shipped extremely far so they have many cost involved to consider as the ordering cost. Moreover, as a result of joint ordering is the best choice for utilizing the ordering cost, this is also the evident support to option 3 to be the best answer for now. 
Table 1. Cycle service level among the options.

\begin{tabular}{lcccc}
\hline Raw & \multicolumn{4}{c}{ Cycle Service Level } \\
\cline { 2 - 5 } Materials & Current Policy & Option 1 & Option 2 & Option 3 \\
\hline RM51 & $100 \%$ & $100 \%$ & $100 \%$ & $100 \%$ \\
RM08 & $100 \%$ & $100 \%$ & $100 \%$ & $100 \%$ \\
RM07 & $100 \%$ & $100 \%$ & $100 \%$ & $100 \%$ \\
RM06 & $100 \%$ & $96.15 \%$ & $100 \%$ & $100 \%$ \\
\hline
\end{tabular}

Table 2. Cost among the options.

\begin{tabular}{lcccc}
\hline Types of & \multicolumn{4}{c}{ Costs (Baht) } \\
\cline { 2 - 5 } Costs & Current Policy & Option 1 & Option 2 & Option 3 \\
\hline Ordering Cost & $1,104,792$ & $1,214,135$ & 907,962 & 838,069 \\
Holding Cost & 289,631 & 138,874 & 172,172 & 143,584 \\
Total Cost & $1,394,423$ & $1,353,009$ & $1,080,134$ & 981,653 \\
\hline
\end{tabular}

\subsection{Application of Systematic Thinking Framework}

We found that the company has the suffering in the current situation by benchmark inventory turnover among the competitors. Then, the main cause, which is revealed from inventory flow, is that the current policy doesn't concern the demand's fluctuation which reflects to actual occurrence. Therefore, we suggest the continuous review system because it covers the concept of fluctuation and it is also suitable with the nature of unsteady demand. The above details are summarized in Fig. 8.

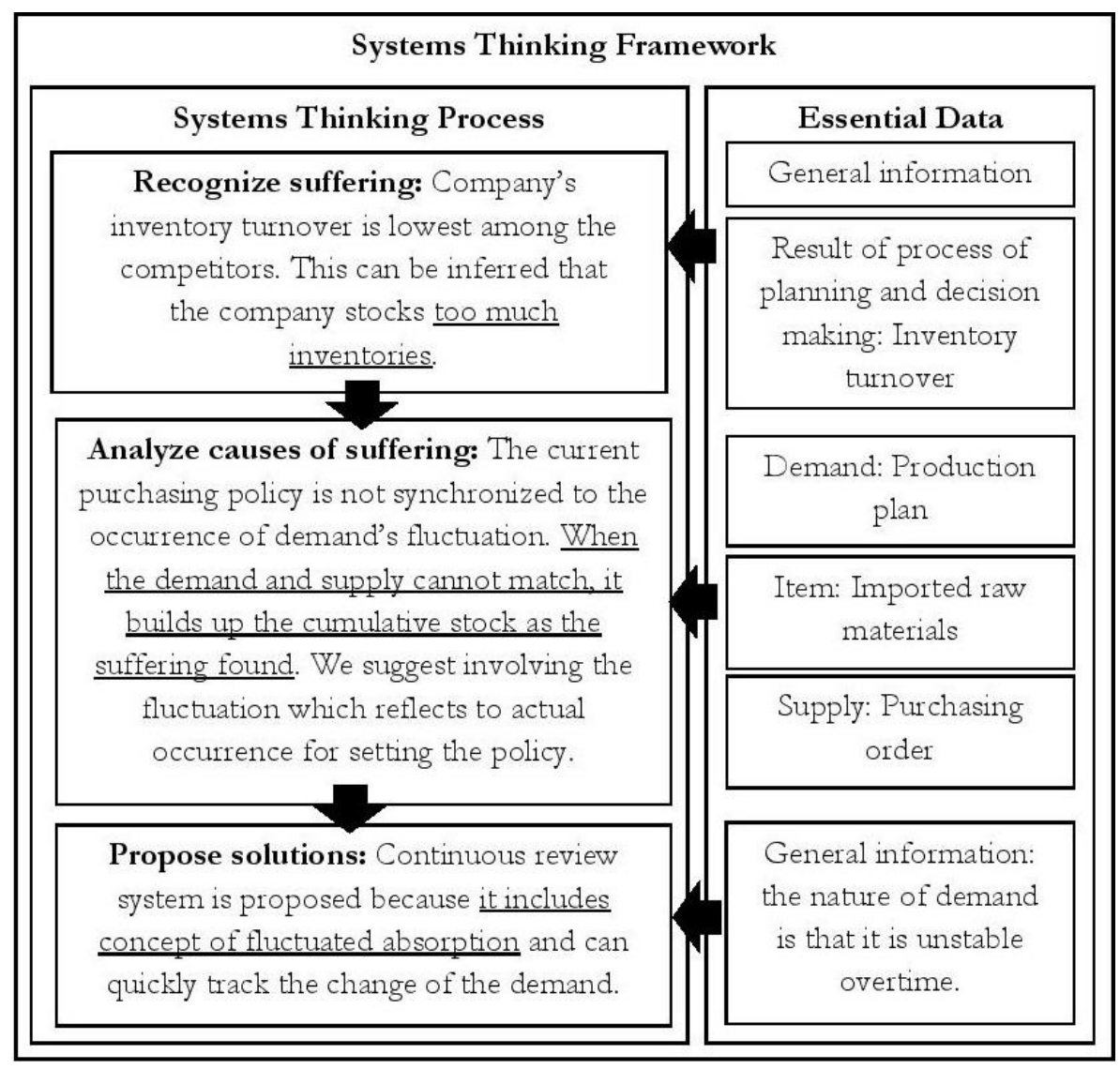

Fig. 8. Application on systems thinking framework in case 1. 


\section{Case Study of Improvement of Tissue Paper Conversion Planning}

The highlight of this case is a high shortage cost. Due to the fact that bargaining power of the customer is higher than the supplier', the competition among the business is strong. Therefore, customers are able to change their mind to other brands easily. This is the main reason of the high shortage cost in the case's situation. According to the high shortage cost, the company needs to stock numerous inventories to support the customers' demand as much as possible. Moreover, tissue paper products are very diverse depending on packaging, purpose of usage, and size; the diversity is also the cause of multiplicity of company's inventories.

The combined effect of the high shortage cost and the diversity affects level of the company's inventories a lot. All previously mentioned are the core of inventory management for this case study. The uniqueness of case's characteristics are discussed as well as the method to design scheduling and inventory management policy for tissue paper products will be presented in the following sections.

\subsection{Recognize Suffering}

\subsubsection{Understand the company's situation}

The company business, the business competitiveness, the competition policy, and the policy to improve inventory management: The Company is a well-known Thailand tissue manufacturing and conversion company. Their Products include of paper hand towels, paper towels, bathroom tissue, facial tissue, and napkins. Each product has many sizes and styles to satisfy the customers' interest. Megastores are the main customers of the company. An online purchasing process is used to connect the transaction between the company and the customers. The product will be delivered to the store within one day after they place a purchase order. This means that customers' lead-time is around one day. Then, after one day pass, the company will be charged following the agreement with customers. The fine seems so high if comparing to price of tissue paper products. In addition, the bad happening more than the fine is a loss of customers' sale. As a result of the commodity products have no barrier among the brands; if the company cannot supply the product, customers may instantly change their mind to other brands instead of waiting. Those are the reason why the company policy is Make To Stock (MTS). It is that because MTS can immediately supply the demand when it exists. Furthermore, in the upcoming quarter, the company aims to reduce cost of inventory management for strengthen their competitiveness.

The manufacturing systems and item's information: There are two sections, i.e., the process of tissue manufacturing and the tissue paper conversion process. The process of tissue manufacturing is continuously for utilizing fixed cost of the production. As, the tissue paper conversion process is MTS for quick response to the customers' demand. According to the shortage cost is very high while the demand of tissue paper products exists in a short time period; the core of management is how the company can supply the demand in time. Thus, in this case, we will mainly focus in managing the conversion process because the tissue paper products, which are used to response the customers' demand, are produced from the conversion process. Conversion machine is a multi-product single machine. It can produce many types of products over time. From the fact that the existence of the single machine results in limited production capacity [19], so it requires a production scheduling to run sequentially on the same machine. Figure 9 shows the manufacturing processes of the tissue paper products. The tissue paper products' production starts from the process of making a big roll tissue paper by passing paper pulp through process of tissue manufacturing. Big roll tissue paper is a main raw material for conversion process, which is the next step of the manufacturing process. Afterward, a roll of paper will be transformed within the conversion machine. Then, the tissue paper products from conversion process are packed and wrapped. Finally, tissue paper products are ready to deliver to the customers.

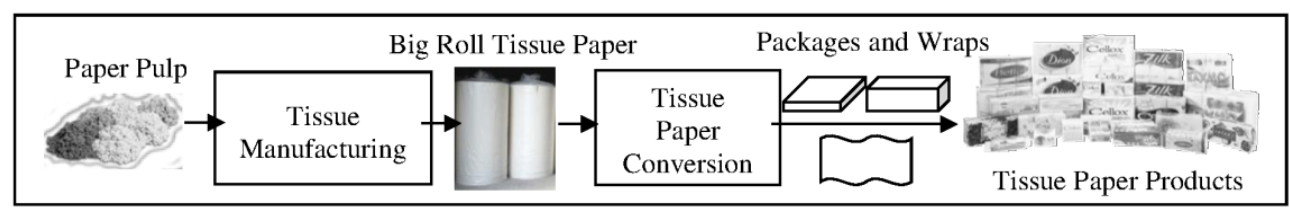

Fig. 9. Manufacturing processes of tissue paper products. 


\subsubsection{Understand the inventory system}

Demand's and item's information: The demand's characteristics following customers' behavior is uncertain. It depends on megastores' experience in forecasting their own customers' demand. However, the company knows that megastore's demand will exist along one day (customers' lead-time is around one day). In supply side, the company will make tissue paper products and stock them following the production planning. Due to tissue paper products are made from the multi-products single machine, which has limited production capacity, so the scheduling is necessarily required.

Supply's information (the current process of planning and decision making): The production planning of tissue paper products is created base on the data of demand forecasting, which are predicted four months ahead for each product. The demand of two week ahead will be confirmed but it can still be adjusted following the actual occurrence such as available raw materials and trend in products' shortage. Afterward, forecasting data will be used to launch weekly production planning for 4 weeks or called a monthly production planning. The plan will be adjusted every week as well as the planning data of week 2 , 3 , and 4 are used to prepare a purchase order concerning lead-time in supplying the raw materials.

Supply's information (the result of using the current process): Figure 10 illustrates the pair data of 10 products. The data consists of inventory levels and service levels of each product. According to the graph in Fig. 10, we found that the warehouse has some types of products too much while some of the other products are not sufficient to support the demand. For example, FG09 has inventory levels to serve the demand up to 32.10 business days while FG05 has inventories levels only for 13.10 days and given service levels just 93.07\%. In fact, if the company stocks inventories too much, cost of holding will be high. Conversely, too low inventories will affect cost of shortage and might be the cause of loss sale as well. Therefore, the suitable level of inventory which balance all involved costs sounds to be the reasonable solution. More than the problem of too much and too low inventories, there is a noise existing in current situation that is many changes of the production planning along a week. In actual, the plan should be followed week by week but now it is changed many times in a week. This is too much trouble for the current workers. In addition, we found that major cause of change is because available inventories cannot match with the customers' demand and the company cannot support high cost of shortage that will occur. Therefore, the change is essentially needed [20].

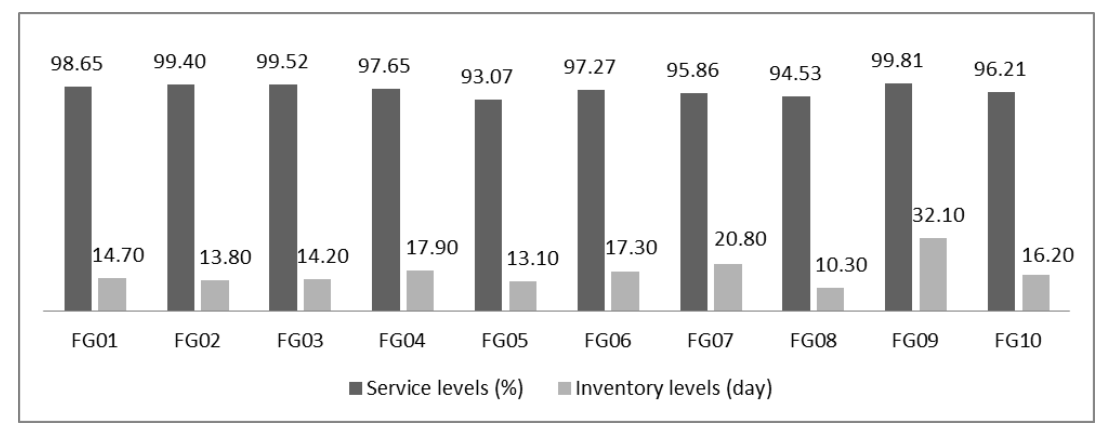

Fig. 10. Manufacturing processes of tissue paper products.

\subsubsection{Compare the result of current process company's target and conclude the suffering}

Inventory levels and service levels are selected to be indicators for recognizing suffering in current company's situation. The result of comparison the data among the tissue paper products found that some products are stocked too much while some of them seem so small. As seen in the difference between service levels of FG05 and FG09. The difference of service levels is $6.74 \%$ while the difference of Inventory levels is up to 19 business days. More than the existent of too much and too small inventories; from the observation, they found that the workers change the production planning many times in a week. Therefore, it leads to a conclusion that there is inventory management problem existing in the company's situation. 


\subsection{Analyze Cause of Suffering}

\subsubsection{Analyze the inventory flow and summarize cause of suffering which leads to the suffering.}

The demand of tissue paper products rises from the megastores. The existent demand will disappear after 1 day pass. Then, the company launches the conversion planning to serve the demand in every week based on the belief in forecasting data. However, the plan can be adjusted under workers' consideration. Afterward, the plan will be fed to the multi-product single machine. Finally, we will get the tissue paper products following the plan. Figure 11 is used to present the conforming characteristics between the demand and the supply of tissue paper products, which are discussed above.

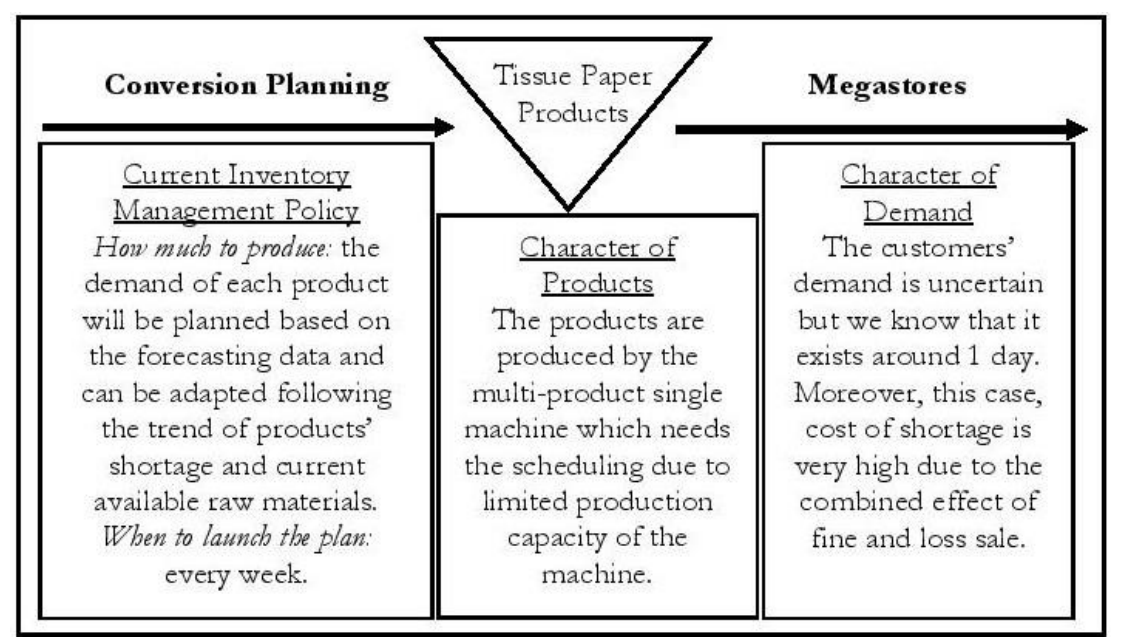

Fig. 11. Inventory flow of tissue paper products.

According to Fig. 11, if we consider the synchronization of the data from the conversion planning to the conversion machine; we found that they are in different levels. The plan shows the amount of each product needed in a week while the machine needs specific data more than weekly plan. It is not only the amount for production, which is needed, but also the production scheduling. Thus, now the workers have to launch the schedule by themselves following their experiences. This seems too suffer for the workers because they have to trade off many constraints and make the decision at the same time.

\subsubsection{Propose the conceptual solution due to cause found}

From the result of analysis of the inventory flow, is it better to have some protocol including decision making for scheduling to release this suffering. In addition, having standard protocol tends to reduce the human error and can quickly adjust the production planning following the changes, which might occur. Continuous effect is to balance inventory levels and service levels among tissue paper products of the company. The balance inventory levels and better service levels will also reduce the company' cost of shortage. Therefore, this conceptual solution leads to solve the problem in current situation quite well.

\subsection{Propose Solution}

\subsubsection{Propose concrete solution due to cause found and the selected nature of the business}

According to the unique characteristic of this case is high cost of shortage, the concept of continuous review system will be introduced for proposing the concrete solution. The major benefit of continuous review system is to quick response to the customers' demand [18]. Therefore, it is a good choice for the scenario of high shortage cost and aiming to response the demand as much as possible. Once the demand exists, inventories are called and the current available stocks are also updated. Until the amount of stock hit ROP, the replenishment will immediately occur. Those are the reason of the continuous review system is better triggering to the actual demand. Then, the first step is to set Reorder Point (ROP) and Economic 
Order Quantity (EOQ) of the products. Afterward, from the analysis step we found that the production scheduling is needed for the multi-product single machine. Therefore, we propose a rolling plan, which is a way for making the priority of scheduling, based on concept of continuous review system. The rolling plan is a plan which is prescribed to run for a certain period of time [21], and in this case, we use the rolling concept to foresee the shortage situation in the future. Brief procedures: current products' stock will be subtracted by a mean of the distribution, which is calculated from the same data used for setting ROP and EOQ. The mean for subtraction is an average demand per day. We will subtract or roll the demand ahead for 4 days and trend of shortage is identified when current products' stock hits ROP after rolling into certain time period. If they hit more than one product, we will pick up the products that have a higher trend to shortage producing first. Moreover, the schedule is updated daily for the reason of quick response to the demand. 4-days of rolling are set from the simulation's result which runs through the historical data as well as it gives the minimum total cost. The simulation's result of the performance between new and current policies is shown in Table 3. The conclusion due to the performance's results from Table 3 is that new solution very working well from all aspects.

Table 3. Cost among the options.

\begin{tabular}{lcc}
\hline Performance indicators & Current policy & Proposed policy \\
\hline Inventory levels (day) & 16.70 & 14.80 \\
Service levels (\%) & 99.41 & 99.99 \\
Changeover times (times) & 83 & 50 \\
Holding cost (baht) & 48,678 & 39,069 \\
Shortage cost (baht) & 79,410 & 1,798 \\
Set up cost (baht) & 114,125 & 68,750 \\
Total cost (baht) & 242,213 & 109,617 \\
\hline
\end{tabular}

To sum up, the proposed policy is a continuous review system and it includes of production scheduling for better synchronization between production planning and machine capacity. The scheduling, which holds to priority of shortage, can effectively support to the customers' demand. As, continuous review system helps to adjust stock of the products concerning to the actual demand. The combined result affects inventory flow becoming more balance. Moreover, those are the direct causes of low inventory levels and better responsibility to the customers' demand. Reflect on the quantitative results, which are presented in Table 3.

\subsection{Application of Systematic Thinking Framework}

Figure 12 shows the overall concept of the framework's application. We found that the company has the suffering in the current situation by comparing inventory level and service level among the company's products. Afterward, the main cause, which leads to suffering, is that the currently planning data isn't compatible with the data required by conversion machine. Therefore, we suggest the concept of production scheduling and continuous review system. The scheduling will help generating the compatible data for planning, while the continuous review system fits for the situation of high shortage cost existing. 


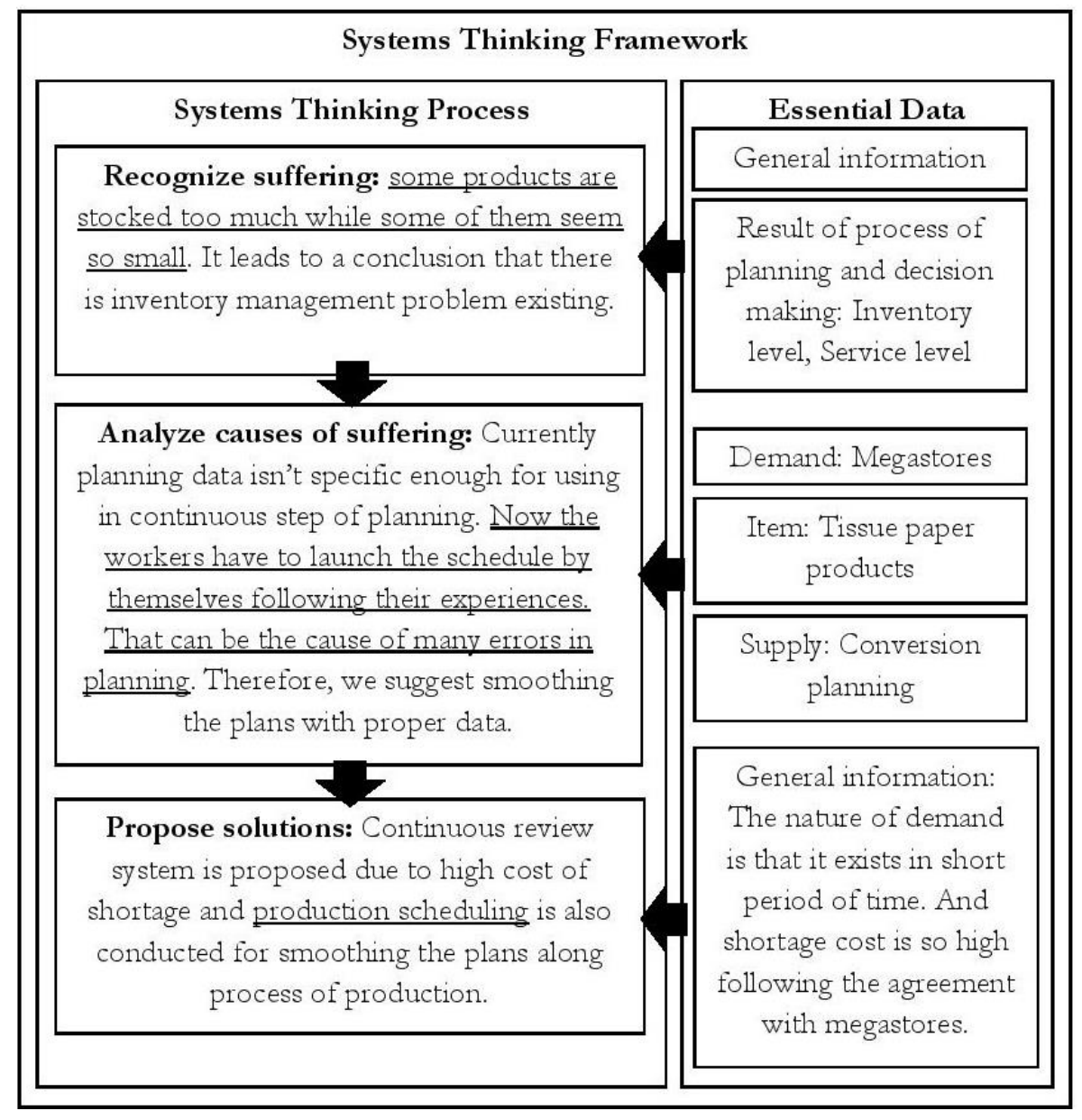

Fig. 12. Application on systems thinking framework in case 2.

\section{Case Study of Equipment Planning Model for Retails Store Network of Coffee-Bakery Shop}

The main characteristic of the case study is that most of the equipment' demand are dependence. It seems easy for managing inventories conforming to the certain demand. However, this characteristic is often disregarded due to the lack of understanding in this special characteristic. Therefore, the analysis of this case will be a meaningful guideline for many companies to effectively deal with the dependent demand.

\subsection{Recognize Suffering}

\subsubsection{Understand the company's situation}

General information: The Company is known as the chief of coffee and bakery business. Most customers tend to have middle and high incomes. The business policy and strategy is that we offer the best product, service, and warm environment to our customers. Thus, key competitiveness consists of the taste, the service, and the environment. Supporting to the market growth in the future, the company launches three plans that are plans of branch expansion, renovation of current stores, and equipment replacement. We name the plans as plan A, B, and C, respectively. The plans are expected to help the company retaining the leadership in the coffee and bakery business.

\subsubsection{Understand the inventory system}

Item's and supply's information (current process of planning and decision making): Three equipment are focused, i.e., the coffee maker (equipment 1), the bread maker (equipment 2), and the DVD player 
(equipment 3). As a result focused equipment is $50 \%$ of overall inventory value of the company; therefore we interest to manage them. Now, the equipment is purchased as follows: 20 pieces in every 3 months, 15 pieces in every 6 months, and 10 pieces in every 6 months for equipment 1,2 , and 3, sequentially. The amount and duration of purchasing are approximately defined by workers' experience and supplier's promotion. Table 4 provides the details of the equipment such as price, lead-time, delivery channels, shipping options, and promotions.

Table 4. Information on the equipment.

\begin{tabular}{lccc}
\hline Equipment & Price (baht) & Lead-time (days) & Delivery Channels \\
\hline Coffee Maker & 250,000 & $50-60$ & Shipping \\
Bread Maker & 35,000 & $50-60$ & Shipping \\
DVD Player & 20,000 & $18-20$ & Air Transport \\
\hline
\end{tabular}

Demand's information: 95\% of equipment' demands arise from three plans which are described previously. The amount and called time of the demand can directly obtain from the plans. The plans rather confirm but there is a little uncertainty. That is an effect from late and early occurrences of the construction plan. This uncertainty will affect called time of the equipment. For example: if the constructions plan of branch 1 early finishes, the equipment' demand for branch 1 will be early called as well. Then, the rest $5 \%$ of the demand are independence. They come from unexpected situations such as accidence (Event D) and disordered function of the equipment (Event E). Actually, we should response independent demand as much as possible because it affects the business policy, which aims to serve the best taste, service, and environment to the customers.

Supply's information (the results of using the current process): We found that inventory value which is used in A.D. 2011 is around 15 million baht. It is $50 \%$ of overall inventory value. This implies that there is $50 \%$ of inventory value which is not used. Furthermore, in the A.D. 2012, products' demand tends to increase up to $85 \%$ of A.D. 2011. If the company still follows principle of current process of the equipment planning, the overall inventory value in A.D. 2012 is possibly up to 56 million baht (30 multiply 1.85). All previously mentioned are summarized as a chart, which is shown in Fig. 13 [22].

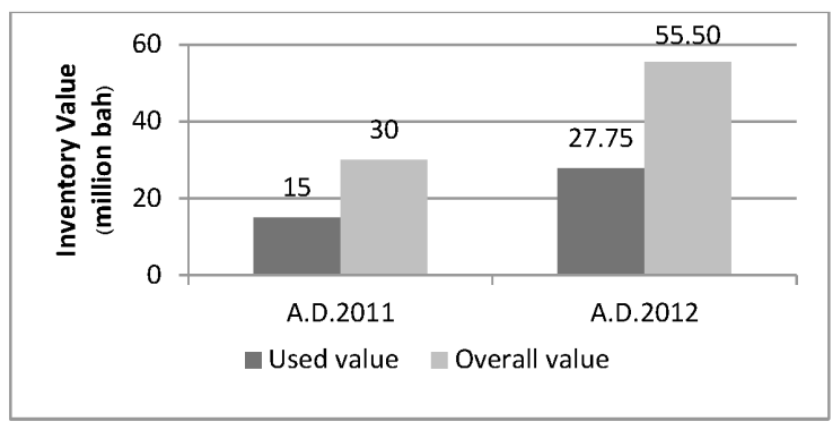

Fig. 13. Inventory value in A.D. 2011 and 2012.

7.1.3. Compare the result of current process company's target and conclude the suffering

Due to results of inventory value of the company show that $50 \%$ of overall inventory value is not used as well as according to the fact that most of demand in this case is predictable; why inventory value is still in high level, even if we certainly know the demand. This question leads to the summary in recognize suffering step that there is something wrong in current inventory management policy of the company. 


\subsection{Analyze Cause of Suffering}

\subsubsection{Analyze the inventory flow and summarize cause of suffering which leads to the suffering}

Demand of the equipment originates from plan A, B, C and event D, E. The plans are rather confirmed while the events are unpredictable. Currently the company supplies the demand by launching the equipment planning, which is approximately defined by workers' experience or followed supplier's promotion. Moreover, we know that equipment 1, 2 have high price and have full container load option for shipping. As equipment 3 is shipped by air as well as it also has a special promotion. All previous discussions are summarized in flow diagram as shown in Fig. 14. Due to the inventory flow, current purchasing policy of equipment 3 is followed supplier's promotion. It seems fine because a price of equipment 3 is low. Thus, an opportunity cost is low as well; it does not matter, if we stock following promotion and replenish when it nearly out of stock. Regarding equipment 1 and 2, current policies are not included information of dependent demand for planning. They just approximate the demand in both facets of quantity and time by workers' experiences. However, they rather know confirmed information about the demand from plan A, B, C.

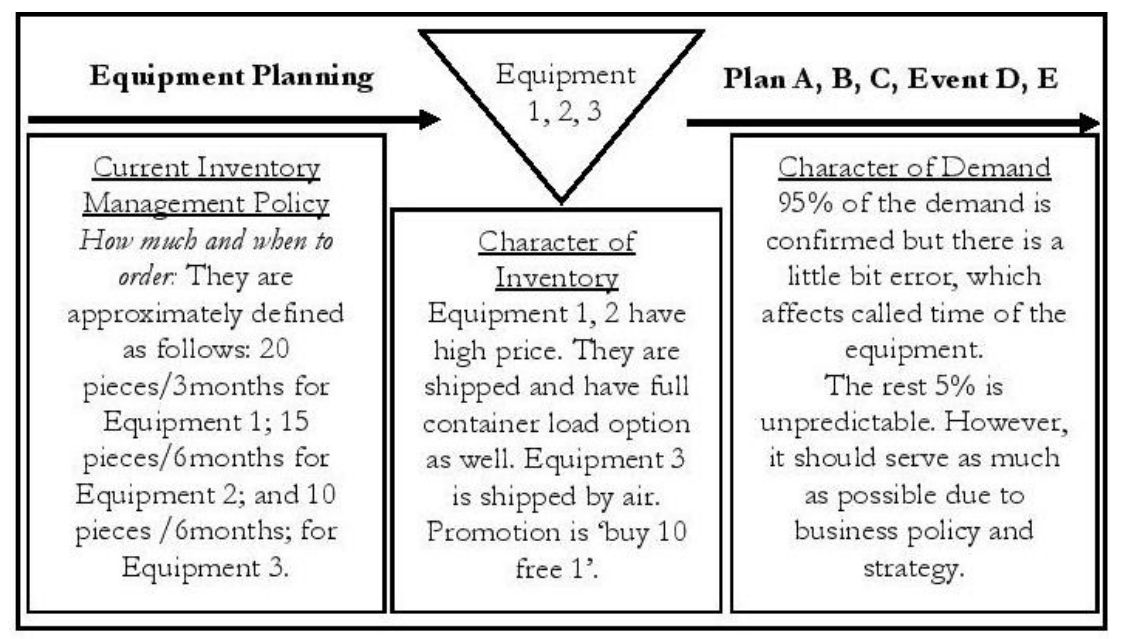

Fig. 14. Inventory flow of the equipment.

\subsubsection{Propose the conceptual solution due to cause found}

The suggestion to relieve current suffering is that the company should include necessary information to set inventory management policy. Afore stated is about managing dependent demand. In part of managing independent demand, basic way to support uncertain demand is to build up safety stock by using historical data. Level of stock, which is built, depends on an acceptant level of the company. In this case, we suggest an average level as a basis. As a result of uncertain demand is only $5 \%$ of all, an average level seems acceptable to the company. For this case, safety stock is mainly used to support uncertain demand from event D and E. However, it can be used as a temporary support for uncertain situation from plan A, B, C as well.

\subsection{Propose Solution}

\subsubsection{Propose concrete solution due to cause found and the selected nature of the business}

The concrete solution for managing dependent demand will be discussed first. According to the demand of equipment 1,2 arise in periods of time, therefore periodic review system is proposed. Moreover, we suggest periodic review system in a short time period for equipment 1 because equipment 1 have high price and high opportunity cost [18]. Therefore, it is better to have stock in low level. Periodic review in every 2 weeks is selected as a policy for equipment 1 as well as 6 weeks review for equipment 2 , which has fair price. Briefly, the period is 2 and 6 weeks for equipment 1, 2 respectively. According to the conceptual solution 
from the previous step, we will also include information of plan A, B, and C to calculate the demand in each reviewing period. Then, purchase order will be placed ahead concerning to the lead-time of supplying. However, at the beginning of each period, equipment should already stand to support the demand along the period. This doing will also support uncertain demand of equipment 1, 2 in case of it early arises before the plans. Next, policy of equipment 3 is remaining the same as current policy because it tends to work well. Finally, proposed policy for independent demand is to build up safety stock concerning the historical data. The reason of both policy for equipment 3 and policy for independent demand are early discussed in analysis step. Results of simulation test between as-is and proposed policy are illustrated in Table 5 and 6 . Proposed policy can reduce cost of current inventory management up to $44.16 \%$ and also decrease cost of current inventory holding up to $72.27 \%$. Reduction of inventory holding cost affects inventory value becoming better. Therefore, suffering in current company's situation can be relieved based on using the proposed solution.

Table 5. Comparison of cost of inventory management between the policies.

\begin{tabular}{lccc}
\hline & \multicolumn{3}{c}{ Cost of Inventory Management (baht) } \\
\cline { 2 - 4 } Equipment & Proposed Policy & As-is Policy & Reduced Cost \\
\hline Coffee Maker & $525,132.85$ & $895,143.00$ & $370,010.15$ \\
Bread Maker & $433,017.15$ & $820,853.00$ & $387,835.85$ \\
DVD Player & - & - & - \\
Total & $958,150.00$ & $1,715,996.00$ & $757,846.00(44.16 \%)$ \\
\hline
\end{tabular}

Table 6. Comparison of cost of inventory holding between the policies.

\begin{tabular}{lccc}
\hline & \multicolumn{3}{c}{ Cost of Inventory Holding (baht) } \\
\cline { 2 - 4 } Equipment & Proposed Policy & As-is Policy & Reduced Cost \\
\hline Coffee Maker & $797,715.93$ & $3,015,803.49$ & $2,218,087.56$ \\
Bread Maker & $469,699.73$ & $1,555,044.55$ & $1,085,344.82$ \\
DVD Player & - & - & - \\
Total & $1,267,415.66$ & $4,570,848.04$ & $3,303,432.38(72.27 \%)$ \\
\hline
\end{tabular}

The proposed policies, which consider the known data and the provided promotion, help to fit the stock level to the demand. Therefore, the stock level reduces and continuous effect lessens cost of inventory holding as illustrated in Table 6 . In practice, when cost of holding is lower, costs of ordering and shortage mostly rise up. However, due to equipment' price are high, so the holding cost becomes the biggest part in overall cost of inventory management. As result of cost of inventory management is also reduced following the proposed policy as shown in Table 5 .

\subsection{Application of Systematic Thinking Framework}

We found that the company has the suffering in the current situation by comparing inventory value between used value and overall value. Afterward, the main cause is that the current algorithm of equipment planning doesn't include the confirmed data which exactly know. As a result of the company have many inventories which are not used, so we suggest that the equipment planning should include the necessary information for consideration. Therefore, periodic review is also applied due to the demand arises in period of time as well as some equipment will purchase following their promotion due to cost advantage's reason. Figure 15 shows the application of the learning framework for analysis case of equipment planning in Coffee-Bakery Shop. 


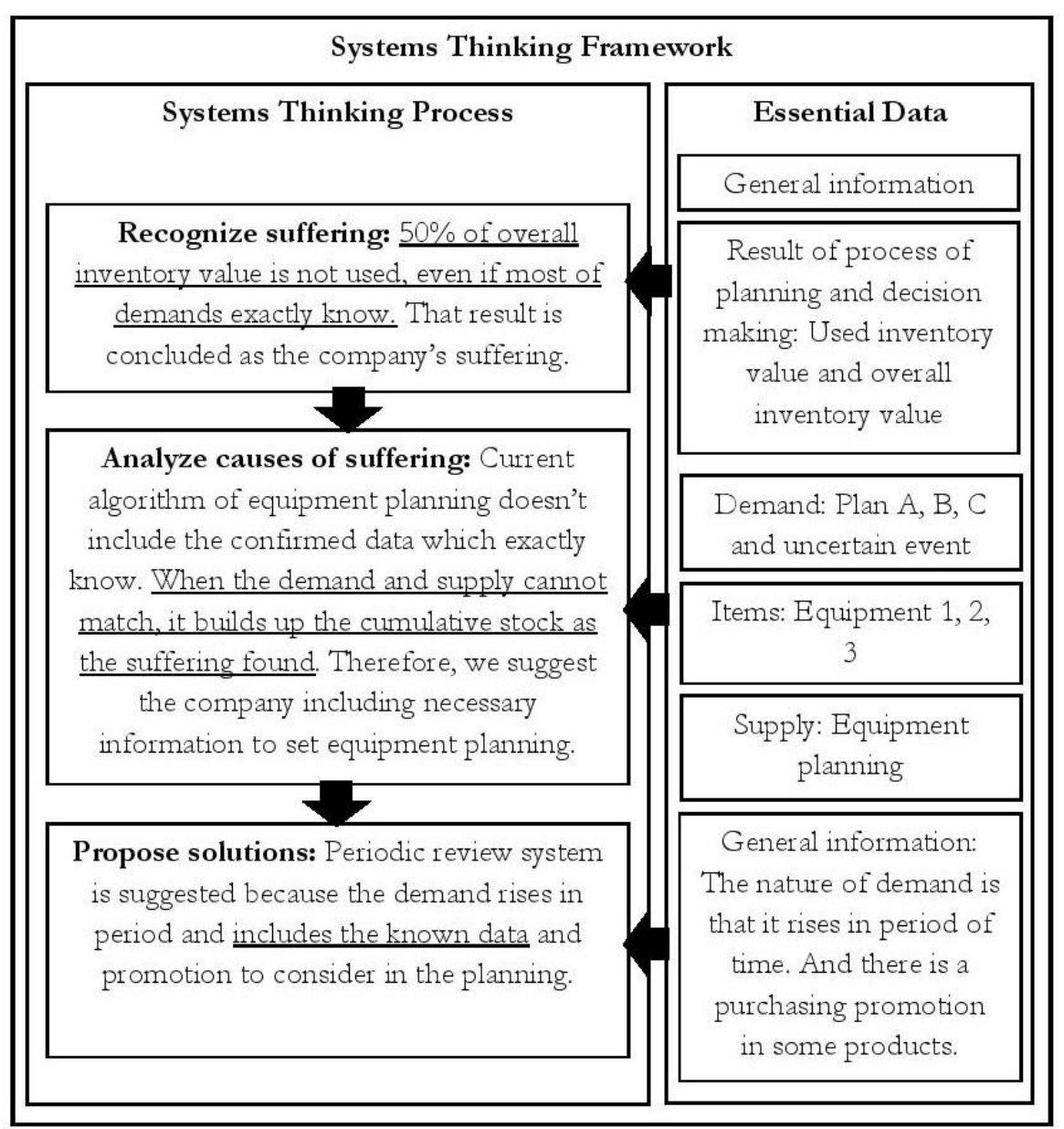

Fig. 15. Application on systems thinking framework in case 3.

\section{Discussion}

The output of this study is the systems thinking framework. It is a tool for enhancing skills to solve inventory management problems. The proposed tool comes with the application for better comprehension. Like any other tools, the practitioners have to take time to build up skills in using this systems thinking framework effectively. One of the practicing ways that we propose is by learning through the case studies as presented in section 5, 6, and 7. A prerequisite knowledge to enhance better learning throughout the case studies for practitioners consists of the understanding of inventory systems, basic knowledge in the inventory models, the performance measures of inventory, and inventory related costs.

Moreover, the practitioners can also try applying the proposed framework with other inventory management problems. We believe that if the practitioners have enough time to practice and gain experiences of usage, they will be able to apply inventory management knowledge better [23]. In addition, after long-run usage, we can obtain more effective feedbacks to improve the systems thinking framework as well.

In the future, we believe that if we can collect more case studies; the knowledge-based system for solving inventory management problems can be built. The various aspects of the problems can be classified in knowledge-based system for easy investigation [24]. Examples of aspects are the characteristics of the problem, the characteristics of the business, and the solution approach. The knowledge-based system will widely make many benefits to all whom have the same interest, such as, the students, the industrial firms, the researchers, and the educators. Additionally, the proposed tool focuses on thinking steps, which has no interactive tools with users. Thus, it is possible to extend concept of our tool to other learning styles that might give better benefits or results in other aspects to the users. 


\section{Acknowledgement}

The research for this paper was financially supported by the Graduate School, Faculty of Engineering, Department of Industrial Engineering, and Resource and Operation Management Research Unit (ROM) of Chulalongkorn University. We are extremely thankful for the support to fund this study.

We also would like to acknowledge Prof. Wanpracha Art Chaovalitwongse, Departments of Industrial and Systems Engineering of the University of Washington, for guidance and feedback on the earlier drafts of this paper and our fruitful cooperation in the improvement of the research.

\section{References}

[1] C. Alexander and J. Watson, Engineering Skills for Career Success. McGraw-Hill Education, 2014.

[2] D. Aronson. (1996). Overview of systems thinking [Online]. Available: http://www.thinking.net/Systems_Thinking/OverviewSTarticle.pdf

[3] D. P. Bertsekas and J. N. Tsitsiklis, "Neuro-dynamic programming: An overview," in Decision and Control, 1995., Proceedings of the 34th on IEEE Conference, 1995, pp. 560-564.

[4] J. R. Stock and D. M. Lambert, Strategic Logistics Management, vol. 4. Boston, MA: McGraw-Hill/Irwin, 2001.

[5] R. N. Charette, "Why software fails [software failure]," Spectrum, IEEE, vol. 42, pp. 42-49, 2005.

[6] B. Vijayaraman and B. A. Osyk, "An empirical study of RFID implementation in the warehousing industry," The International Journal of Logistics Management, vol. 17, pp. 6-20, 2006.

[7] A. R. Ravindran, Operations Research Methodologies. CRC Press, 2008.

[8] R. Gordon, "Balancing real-world problems with real-world results," Phi Delta Kappan, vol. 79, p. 390, 1998.

[9] W. Kohler, "The mentality of apes," 1924.

[10] H. A. Simon, "The structure of ill-structured problems," in Models of Discovery. Springer, 1977, pp. 304325.

[11] M. Abramovitz, "Inventory policy and business stability," in Regularization of Business Investment: Princeton University Press/NBER, 1954, pp. 283-298.

[12] T. Morden, Principles of Management: Ashgate Burlington, 2004.

[13] T. Benjaboonyazit, "Systematic Approach to Problem Solving of Low Quality Arc Welding during Pipeline Maintenance Using ARIZ (Algorithm of Inventive Problem Solving)," Engineering Journal, vol. 18, no, 4, pp. 113-133, 2014.

[14] T. Benjaboonyazit, "Systematic approach to arowana gender identification problem using algorithm of inventive problem solving (ARIZ)," Engineering Journal, vol. 18, no. 2, pp. 13-28, 2014.

[15] W. Bauer, W. Biedermann, B. Helms, and M. Maurer, "A student laboratory for systems engineering: Teaching systems engineering to students without previous SE-knowledge based on an industryoriented example," in Systems Conference (SysCon), 2012 IEEE International, 2012, pp. 1-6.

[16] S. Jongsawadviboon, "Design of purchasing management for imported materials," Master's thesis, Department of Industrial Engineering, Faculty of Engineering, Chulalongkorn University, Thailand, 2012.

[17] R. J. Tersine, Principles of Inventory and Materials Management. Prentice-Hall, 1994.

[18] M. K. Starr and D. W. Miller, Inventory Control: Theory and Practice: Prentice-Hall, 1962.

[19] A. Taleizadeh, L. Cárdenas-Barrón, J. Biabani, and R. Nikousokhan, "Multi products single machine EPQ model with immediate rework process," International Journal of Industrial Engineering Computations, vol. 3, pp. 93-102, 2012.

[20] P. Rungchawalnon, "Improvement of tissue paper conversion planning," Master's thesis, Department of Industrial Engineering, Faculty of Engineering, Chulalongkorn University, Thailand, 2010.

[21] K. R. Baker, "An experimental study of the effectiveness of rolling schedules in production planning," Decision Sciences, vol. 8, pp. 19-27, 1977.

[22] S. Pinitnorachai, "Equipment planning model for retails store network-Coffee and bakery shop," Master's thesis, Logistics Management, Chulalongkorn University, Thailand, 2011.

[23] E. M. Boyd and A. W. Fales, "Reflective learning key to learning from experience," Journal of Humanistic Psychology, vol. 23, pp. 99-117, 1983. 
[24] R. Studer, V. R. Benjamins, and D. Fensel, "Knowledge engineering: principles and methods," Data \& Knowledge Engineering, vol. 25, pp. 161-197, 1998. 